\title{
Therapeutic management of milk fever with retained placenta in Holstein Friesians cow in a private dairy farm at Sheikhupura, Punjab-Pakistan
}

\author{
Yadullah Baqiira, Asfa Sakhawat ${ }^{\mathrm{b}}$, Adnan Yousaf ${ }^{\mathrm{c}}$, Rida Tabbasum ${ }^{\mathrm{b}}$, Tayyba Awais ${ }^{\mathrm{b}}$, Sindhu \\ Baloch $^{c}$, Asghar Subhani ${ }^{d}$, Faiza Rubab ${ }^{c}$, Shah Jahan Musakhaile, Rehana Shahnawaz ${ }^{c}$, Abdul \\ Latif Bhuttoc, Inayatullah Sarkic, Mamoona Arshad ${ }^{\mathrm{b}}$
}

\begin{abstract}
${ }^{\text {aDepartment }}$ of Agriculture Science, Allama Iqbal Open University Islamabad-Pakistan.
bFaculty of Veterinary Science, University of Veterinary and Animal Sciences Lahore-Pakistan.

'Faculty of Animals Husbandry and Veterinary science, Sindh Agriculture University Tandojam-Pakistan.

dFaculty of Veterinary Science, University of Agriculture Faisalabad-Pakistan.

eLivestock and Dairy Development Department, Quetta-Pakistan.
\end{abstract}

\begin{abstract}
Milk fever is a condition in which an animal's body fails to maintain calcium homeostasis as a result of an increase in calcium demand during pregnancy or lactation. The clinical care of probable milk fever with the retained placenta in a Friesian cow following twin calves was described in this case. The principal complaint of a four-yearold Holstein Friesian cow weighing $450 \mathrm{~kg}$ was weakness and inability to stand a day after the birth of two calves. The cow was found to be in sternal recumbency and unable to stand, with the placenta hanging from the vulva region. The cow's vital signs were all normal, but she had a weak heartbeat. Milk fever, downers' cow syndrome, and hypophosphatemia were the differential diagnosis at the time. Based on the history of parturition of two calves and thus hypocalcemia, the cow was diagnosed with probable milk fever. Flunixin meglumine $1.1 \mathrm{mg} / \mathrm{kg}$ was given intravenously to the cow as an anti-inflammatory, anti-pyrexia, and analgesic. Then, as a calcium supply, $500 \mathrm{~mL}$ of calcium borogluconate (23\%) was slowly supplied intravenously at a rate of $1 \mathrm{drop} / \mathrm{second}$. After 10 minutes, the cow responded to the treatment. In addition, the retained placenta was irrigated with $0.9 \%$ normal saline lavaged into the uterus. As a last lavage, $20 \mathrm{~mL}$ of oxytetracycline $(20 \mathrm{mg} / \mathrm{kg})$ was injected into the uterine body. Finally, to avoid additional bacterial infections, a broad range long-acting oxytetracycline $(20 \mathrm{mg} / \mathrm{kg})$ antibiotic was given intramuscularly once. During the treatment of milk fever, the major focus should be on therapeutic treatment to restore the calcium level in the blood.
\end{abstract}

KEYWORDS: calcium borogluconate; Holstein Friesian cow; Punjab; twin calves.

Accepted May 29, $2021 \quad$ Published online July 31, 2021

Cite this article: Baqir et al. (2021) Therapeutic management of milk fever with retained placenta in Holstein Friesians cow in a private dairy farm at Sheikhupura,

Punjab-Pakistan. Multidisciplinary Science Journal 3: e2021015, doi:10.29327/multiscience.2021015.

\section{Introduction}

Due to their large milk production, the Friesian cow breed is widely used in the dairy sector around the world (Bhanugopan et al 2014). They are usually recognized by their black and white color pattern (Bhanugopan et al 2014). Nonetheless, high-producing cattle are frequently affected with milk fever, a metabolic condition (Adams et al 1996). Milk fever, also known as hypocalcemia, parturient paresis, or eclampsia, is a condition in which the animal's body fails to maintain calcium homeostasis after a rapid increase in calcium demand during pregnancy or breastfeeding (Cecilia et al 2014). 
Milk fever in dairy cattle can be caused by five different things:

1. Sudden calcium loss in the blood in high producers or cows carrying twins.

2. Excess calcium in the diet during the third trimester, resulting in hypocalcemia due to parathyroid gland atrophy, resulting in low calcium absorption.

3. Phosphorus deficiency in the diet.

4. Hypomagnesaemia is a condition in which there is a lack of magnesium in the body.

5. Metabolic alkalosis, which causes a change in the parathyroid hormone receptor, resulting in a decrease in calcium absorption (NRC 2001; Bhanugopan et al 2014)

The failure of the complete or partial placenta to be evacuated over a period of time that is deemed to be longer than normal physiologic limitations is known as retained fetal membranes (Zebeli et al 2013). This is one of the most prevalent problems in animals after they have given birth (Chapinal et al 2011). If fetal membranes are not expelled within 8 to 12 hours following calving in ruminants, they are considered pathologically maintained in the cow (Goff et al 2008). Following normal parturition, the prevalence of retained fetal membranes in dairy cattle ranges from $3 \%$ to $12 \%$ (Goff et al 2008). Milk fever causes uterine muscular atony, which predisposes to the retention of fetal membranes since calcium is required for muscle contraction in the uterus (DeGaris et al 2008). The clinical care of milk fever with the retained placenta in a Friesian cow after twin calves is described in this case.

\section{History}

The principal complaint of a four-year-old Friesian cow weighing $450 \mathrm{~kg}$ was weakness and inability to stand a day after the birth of two calves. The cow was well-cared for, and her vaccination and deworming records were up to date. The cow was a high-yielding animal, capable of producing 30 liters of milk each day.

\section{Physical examination of Friesian cow}

According to an observational examination, the cow was in sternal recumbency and unable to stand, with the placenta hanging from the vulva region. The cow, on the other hand, was still alert and regurgitating. All vital indicators were within normal limits during the physical examination, although the cow had a weak heart rhythm. Furthermore, when the limbs were palpated, they were stiff and cold. Milk fever, Downers' cow syndrome, and hypophosphatemia were the differential diagnosis at the time.

\section{Diagnosis and treatment}

The diagnosis of milk fever was based on the cow's history of giving birth to two calves and the fact that she was a high-producing animal, which could lead to hypocalcemia. The main therapy strategy in this situation was to raise the calcium level in the blood. Initially, flunixin meglumine $(1.1 \mathrm{mg} / \mathrm{kg})$ was given intravenously as an anti-inflammatory, anti-pyrexia, and analgesic treatment. Then, as a calcium supply, $500 \mathrm{~mL}$ of calcium borogluconate (23\%) was slowly supplied intravenously at a rate of $1 \mathrm{drop} / \mathrm{second}$. After 10 minutes of calcium borogluconate delivery, the heart rate sound became louder. In addition, muscular twitching and urination were seen. In addition, the uterus was lavaged and irrigated with $0.9 \%$ normal saline to treat the retained placenta. The final lavage was $20 \mathrm{~mL}$ of oxytetracycline $(20 \mathrm{mg} / \mathrm{kg})$ pumped into the uterine body. Finally, once intramuscularly, broad-spectrum and long-acting oxytetracycline (20 $\mathrm{mg} / \mathrm{kg}$ ) was given to treat present infections and prevent secondary bacterial infections.

\section{Progression}

The cow responded well to the therapies, and the case was followed up on the next day after treatment. The cow looked bright and alert, and she stood on all four legs. There was no flow from the vulva since the placenta had detached. The cow's prognosis was good in this case. Thus, the second therapy of calcium borogluconate $23 \%$ was given intravenously. The cow's owner was instructed to just do partial milking for a few days in order to restore the calcium level and avoid mastitis. 


\section{Discussion}

Milk fever can manifest itself in three different ways in dairy cows (Khan et al 2015). The cow is still ambulatory at this stage, but it may appear restless and shuffle its hind limbs frequently. The affected cow will be ataxic, with tiny tremors in the flanks and triceps. The cow is unable to stand but may maintain its sternal recumbency. Furthermore, the most conspicuous clinical response at this stage is tachycardia, although with reduced heart sound intensity. The animal may also have a " $\mathrm{S}$ " bend in its neck, where it tucks its head under the trunk, a dry muzzle, cold extremities, and a temperature below normal (Greg et al 1998).

The cow appeared to be in early milk fever in this case, with just sternal recumbency, a feeble heart sound, and cold hind limbs. Milk fever develops when a cow gradually loses consciousness until it is comatose (Miltenburg et al 2016). During this stage of milk fever, it will be possible to notice lateral recumbency, full muscle flaccidity, and a lack of response to stimuli (Finbar et al 2006). Laboratory confirmation for the diagnosis of milk fever is often unnecessary (Miltenburg et al 2016) when treatment responses are helpful for the final diagnosis. As seen in this scenario, a cow treated with calcium borogluconate will begin urinating as the intensity of heart sounds increases (Gammon et al 2014). Nonetheless, detecting the calcium content in the blood can be used to confirm the diagnosis. A cow's normal serum calcium concentration ranges from 2.2 to $2.7 \mathrm{mmol} / \mathrm{L}$, whereas the parameter in milk fever is less than $1.5 \mathrm{mmol} / \mathrm{L}$ (Mulligan et al 2006). Calcium is required to release acetylcholine, which facilitates nerve impulse transmission at the myoneural junction, whereas hypocalcemia inhibits smooth and cardiac muscle contractility (Roberts et al 2012). This could be the cause of the retained placenta in this case, as calcium is also required for uterine contraction, and a decrease in or absence of contraction will result in placenta retention. Secondary bacterial infection, on the other hand, could play a role in the formation of a retained placenta (Reinhardt et al 2011). In situations with retained placenta, therapeutic therapy with oxytetracycline improves prognosis and prevents subsequent bacterial infection, which was present in this case. To avoid muscle and nerve harm, milk fever must be treated as quickly as possible with the goal of restoring serum calcium concentration (Wubishet et al 2016).

Milk fever is commonly treated with a $2 \mathrm{~g} / 100 \mathrm{~kg}$ calcium borogluconate intravenous injection or a $1.5 \mathrm{~g}$ calcium subcutaneous injection (Wal 1983; Oetzel 1988). Intravenous administration, on the other hand, is always the preferred method of treatment due to its high and rapid absorption rate. This was clear in this example, as the heart rhythm quickly improved after a few minutes of intravenous calcium delivery. Furthermore, adding magnesium to a calcium borogluconate solution will aid in enhancing calcium absorption by activating parathyroid hormone receptors.

Milk fever can be avoided in a variety of ways, all of which improve calcium homeostasis. These include:

- Supplying a low calcium diet to dairy cows throughout the third trimester.

- Feeding a high magnesium diet,

- Feeding a low potassium diet to avoid metabolic alkalosis.

- Injecting vitamin D 10 to 14 days before calving to avoid hypocalcemia (Adams et al 1996).

\section{Conclusion}

A case of milk fever in a postpartum cow was successfully treated with calcium borogluconate, and the prognosis was good, according to this case report. Milk fever develops before, during, or after birth as a result of a metabolic calcium imbalance in the blood. During the treatment of milk fever, the major focus should be on therapeutic treatment to restore the calcium level in the blood. Cows treated quickly have a better prognosis, reducing mortality and resulting in financial losses for the dairy business.

\section{Conflict of Interest}

The authors declare no conflict of interest.

\section{Funding}

This research did not receive any financial support. 


\section{References}

Adams R, Ishler V, Moore D (1996) Trouble-shooting milk fever and downer cow problems. DAS. IVEF 216:1-7.

Bhanugopan MS, Lievaart J (2014) Survey on the occurrence of milk fever in dairy cows and the current preventive strategies adopted by farmers in New South Wales, Australia. Aust. Vet. J. 92:200-205.

Cecilia K (2011) Minerals to Dairy Cows with Focus on Calcium and Magnesium Balance. Doctoral Thesis Swedish University of Agricultural Sciences Uppsala.

Chapinal N, Carson M, Duffield TF, Capel M, Godden S, Overton M, Santos JE, LeBlanc SJ, (2011) The association with serum metabolites with clinical disease during the transition period. J. Dairy. Sci. 94:4897-4903.

DeGaris PJ, Lean IJ (2008) Milk fever in dairy cows: a review of pathophysiology and control principles. Vet. J. 176:58-69.

Finbar M, Luke OG, Desmond R, Michael D (2006) Production diseases of the transition cow: Milk fever and subclinical hypocalcemia. Irish Veterinary Journal 59:697-702.

Gammon D (2014) Milk fever prevention: a clinical review of current prevention strategies. Livestock 19142-146.

Goff JP (2008) The monitoring, prevention, and treatment of milk fever and subclinical hypocalcemia in dairy cows. Vet. J. 176:50-57.

Greg B, Rick V, John F.S (1998) Controlling Milk Fever and Hypocalcemia in Dairy Cattle: Use of Dietary Cation Anion Difference (DCAD) in Formulating Dry Cow Rations. Technical Report of Extension Dairy Specialist, 1998, Kansas State University.

Khan A, Mushtaq MH, Khan AW, Chaudhry M, Hussain A (2015) Descriptive epidemiology and seasonal variation in prevalence of milk fever in KPK (Pakistan). Global Veterinarian 14:472-477.

Miltenburg CL, Duffield TF, Bienzle D, Scholtz EL, and LeBlanc SJ (2016) Randomozed clinical trial of a calcium supplement for improvement of health in dairy cows in early lactation. Journal of Dairy Science 16:31-37.

Mulligan FJ, Grady LO, Rice DA, Doherty ML (2006) A herd health approach to dairy cow nutrition and production diseases of the transition cow. Animal Reproduction Science 96:331-353.

National Research Council (NRC) (2001) Subcommittee on dairy cattle nutrition. In nutrient requirements of dairy cattle, 7th Eds. National academy press, Washington DC.

Oetzel GR (1988) Parturient paresis and hypocalcemia in ruminant livestock. Vet. Clin. North Am. Food Anim. Pract. 4:351-364.

Roberts T, Chapinal N, LeBlanc SJ, Kelton DF, Dubuc J, Duffield TF (2012) Metabolic parameters in transition cows as indicators for early lactation culling risk. J. Dairy Sci. 95:3057-3063.

Reinhardt TA, Lippolis JD, McCluskey BJ, Goff JP, Horst RL (2011) Prevalence of subclinical hypocalcemia in dairy herds. Vet. J. 188:122124.

Wal RC (1983) Daniel, Motility of the rumen and abomasum during hypocalcemia. Can. J. Comp. Med. 47:276.

Wubishet F, Dechassa T, Nejash A, Wahid MA (2016) Milk Fever and its Economic Consequences in Dairy Cows: A Review. Global Veterinaria 16:441-452.

Zebeli Q, Beitz DC, Bradford BJ, Dunn SM, Ametaj BN (2013) Peripartial alterations of calcitonin gene-related peptide and minerals in dairy cows affected by milk fever. Veterinary Clinical Pathology 42:70-77. 